\title{
(6) OPEN ACCESS \\ Learning curve of Wingspan stenting for intracranial atherosclerosis: single-center experience of 95 consecutive patients
}

\author{
Simon Chun Ho Yu, ${ }^{1}$ Thomas Wai Hong Leung, ${ }^{2}$ Kwok Tung Lee, ${ }^{1}$ \\ Lawrence Ka Sing Wong ${ }^{2}$
}

1Department of Imaging and Interventional Radiology, Vascular and Interventional Radiology Foundation Clinical Science Center, The Chinese University of Hong Kong, Hong Kong, China ${ }^{2}$ Department of Medicine and Therapeutics, The Chinese University of Hong Kong, Hong Kong, China

\section{Correspondence to} Professor Simon Chun Ho Yu, Department of Imaging and Interventional Radiology, The Chinese University of Hong Kong, Prince of Wales Hospital, 30-32 Ngan Shing Street, Shatin, The New Territories, Hong Kong 852, China; simonyu@cuhk.edu.hk

Received 16 November 2012 Revised 14 February 2013 Accepted 27 February 2013 Published Online First 20 March 2013

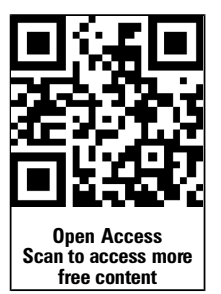

To cite: $\mathrm{Yu} \mathrm{SCH}_{\text {, }}$ Leung TWH, Lee KT, et al. J Neurolntervent Surg 2014;6:212-218.

\section{ABSTRACT \\ Background Symptomatic brain hemorrhage was a significant cause of periprocedural stroke or death following stenting in the Stenting and Aggressive Medical Management for Preventing Recurrent Stroke in Intracranial Stenosis trial, which called into question the safety of Wingspan stenting for intracranial \\ atherosclerosis. This study analyzed the role of a learning curve in the safety and outcome of Wingspan stenting from the experience of 95 consecutive patients at a single center.}

Methods In this prospective study the endpoints were major stroke or death (modified Rankin Scale score $>3$ ) within 30 days, other neurological complications, technical procedural problems, technical success in completion of angioplasty and stenting and recurrent ischemic stroke in the corresponding vascular territory after 30 days. Data splitting into quarters was used for learning curve analysis.

Results The periprocedural major stroke or death rate was $4.2 \%$ (4/95), minor stroke rate was 5.3\% (5/95), total $9.5 \%(9 / 95)$. The technical procedural problem rate was $11.6 \%(11 / 95)$ and the technical success rate was $93.7 \%$ (89/95). The 89 patients were followed for 38.9 \pm 22.7 months (median 40.8 , range $0.2-72$,

3463 patient-months) after stenting. The risk of recurrent ischemic stroke in the corresponding vascular territory was $0.7 \%$ per patient per year (2/3463 patient-months). Guidewire- or angioplasty-related hemorrhage was the major cause of periprocedural major stroke or death $(3 / 4,75 \%)$ and did not occur in the last quarter. Periprocedural intracerebral hemorrhage was uncommon and perforator stroke did not occur.

Conclusions There may be a learning curve for mastering the safety precautions of Wingspan stenting for intracranial atherosclerosis.

\section{INTRODUCTION}

Intracranial atherosclerotic stenosis accounts for approximately $8-10 \%$ of cases of ischemic stroke in the USA ${ }^{1} 2$ and $33 \%$ of cases in Asia. $^{3}$ Angioplasty and stenting has been considered beneficial in preventing recurrent stroke in patients with symptomatic and severe intracranial stenosis $(\geq 70 \%),{ }^{4}$ but this belief has been questioned since the publication of the Stenting and Aggressive Medical Management for Preventing Recurrent Stroke in Intracranial Stenosis (SAMMPRIS) trial, the first randomized controlled trial on stenting versus medical therapy for intracranial arterial stenosis. The trial indicated that aggressive medical management was superior to stenting using the Wingspan system in preventing recurrent stroke, ${ }^{5}$ partly because the periprocedural stroke or death rate within 30 days after Wingspan stenting $(14.7 \%)$ in the trial was unacceptably high and substantially higher than the rates reported in early studies $(4.5-9.6 \%){ }^{6-8}$ Although the high rate of periprocedural complications was attributed by the authors of the SAMMPRIS trial to the inclusion of patients with recent symptoms that were known to be associated with an increased risk of distal embolism during stenting, ${ }^{9} 10$ there were a number of causes of symptomatic periprocedural stroke including $63.3 \%(19 / 30)$ ischemic stroke and $37.7 \%(11 / 30)$ hemorrhagic stroke. While factors such as the timing and dosing of the clopidogrel load, the size of the core infarct prior to stenting and perioperative blood pressure management could be causes of hemorrhagic complications, complications due to the technical aspect of the stenting procedure remain a possible cause and warrant further studies.

The objective of this study was to analyze the role of a learning curve factor in the safety and outcome of Wingspan stenting based on the experience with 95 consecutive patients in a single center.

\section{METHODS}

\section{Study design}

This prospective single-center study was approved by the institutional review board. From February 2006 to October 2011, 3240 patients with ischemic stroke or a transient ischemic attack (TIA) presenting to the institution were assessed and investigated. Ninety-five patients who fulfilled all the following inclusion criteria underwent angioplasty and stenting and were followed to the time of analysis in February 2012. The inclusion criteria included: (1) stenosis $\geq 70 \%$ and ischemic stroke or TIA; or (2) stenosis $\geq 50 \%$ and recurrent ischemic stroke or TIA despite medical therapy; and (3) minor ischemic stroke with potentially salvageable cerebral function, mentally sound enough to give their own consent and cooperate during the procedure with National Institutes of Health Stroke Scale (NIHSS) score $\leq 8$ and baseline modified Rankin Scale (mRS) score $\leq 3$; (4) stenosis confirmed by digital subtraction angiography (DSA); (5) location of the stenosis corresponding to the vascular territory of the ischemic event; 
(6) diameter of the vessel immediately adjacent to the stenosis $\geq 2 \mathrm{~mm}$; (7) length of each stenosis $\leq 14 \mathrm{~mm}$; and (8) written informed consent obtained for the procedure and the study. Patient inclusion was not limited to those with a symptomatic event presenting within 30 days because we presumed angioplasty and stenting would be beneficial to the patients for stroke prevention as long as there were recurrent ischemic symptoms despite medical therapy. Exclusion criteria included: (1) nonatherosclerosis stroke etiology such as cardiogenic embolism, Moyamoya disease or vasculitis; (2) sizeable cerebral infarct (more than one-third middle cerebral artery (MCA) territory) at risk of hemorrhagic conversion; (3) contraindication to antiplatelet therapy such as bleeding diathesis, active peptic ulcer or a history of intracerebral hemorrhage; or (4) concurrent intracranial pathology such as tumor, arteriovenous malformation or aneurysm. Morphologically high-risk patients were not excluded from angioplasty and stenting.

\section{Study endpoints}

The primary endpoint was periprocedural major stroke or death within 30 days. The incidence and causes of the major stroke, which was defined as any stroke with mRS score 4-6, were studied. The secondary endpoints were other periprocedural neurological complications within 30 days, technical problems encountered during the procedure, technical success of the procedure and ischemic stroke in the corresponding vascular territory during the follow-up period. A technical problem was defined as any technical situation that significantly hinders the procedures of angioplasty and stenting and seriously affects the success of the procedure. Technical success was defined as successful completion of the procedure of angioplasty and stenting at the site of stenosis.

\section{Treatment procedure}

The procedure was performed under local anesthesia without sedation; this practice was partly due to limited resources of general anesthesia in our institution and it also allowed monitoring of ischemic symptoms during the procedure. Three-dimensional rotational angiography (3DRA) was used for the assessment of stenosis and selection of optimal projections for biplane fluoroscopic guidance. Biplane angiographic equipment (Integris BV5000) was used for the first 59 patients and Allura Xper FD 20/20 for the rest (Philips Medical Systems, The Netherlands). All the procedures were performed by a constant team of an interventional neuroradiologist with 8 years of experience in endovascular neurointervention (SCHY) and an interventional neurologist with 1 year of experience (TWHL) at the onset of the study. Instruments included a 6 Fr guiding catheter, extracranial catheters (Guider Softip XF, Boston Scientific Corporation (BSC), Plymouth, Minnesota, USA or Shuttle-SL, Flexor Tuohy-Borst Sidearm Introducer, Cook Medical, Bloomington, Indiana, USA) or intracranial catheters which were placed in the intracranial internal carotid artery (ICA) or cervical vertebral artery (Neuron Delivery Catheter 053, Penumbra, Alameda, California, USA); micro guidewire $160 \mathrm{~cm}$ and $300 \mathrm{~cm}$ long (Transend Floppy $160 \mathrm{~cm}$ and $300 \mathrm{~cm}, \mathrm{BSC}$ ); support wires (V18, BSC); microcatheter (Excel 14, BSC); and angioplasty balloon catheter (Gateway, BSC). The criteria for selection of the size of angioplasty balloon and Wingspan stent were the same as that previously described. ${ }^{6-8}$ However, we used a short balloon inflation time of $\leq 10 \mathrm{~s}$ because the patients were not under general anesthesia and might not tolerate the ischemia during a long balloon inflation time. All patients were treated with daily oral aspirin $100 \mathrm{mg}$ and clopidogrel $75 \mathrm{mg}$ for at least 3 days before the procedure. A moderate dose of heparin (2500 IU) as an intravenous bolus was administered during the procedure to maintain an activated clotting time of $180-250 \mathrm{~s}$ and was not reversed at the end of the procedure. After the procedure, daily oral aspirin $100 \mathrm{mg}$ and clopidogrel $75 \mathrm{mg}$ were prescribed for 3 months and subsequently daily oral aspirin $100 \mathrm{mg}$ was continued life-long. The systolic blood pressure was stabilized at levels of $120-130 \mathrm{~mm} \mathrm{Hg}$ before discharge.

\section{Outcome assessment}

Details of all individual procedures including specific instruments, the technical process of the procedure and problems encountered during the procedure were documented. Neurological symptoms during the periprocedural and follow-up period were assessed and documented by neurologists who were not involved in the study for evidence of ischemic or hemorrhagic stroke, which was confirmed with CT or MRI by independent neuroradiologists. A research assistant blinded to the study was responsible for capturing all the clinical and radiological data of all the patients to ensure all the complications were included.

\section{Outcome of patients treated with medical therapy}

From the group of 3240 patients who presented to the institution during the same period, we selected those who had atherosclerotic intracranial stenosis $\geq 70 \%$ and received only medical therapy as a control group for evaluation of treatment outcome. Medical therapy consisted of aspirin $80 \mathrm{mg}$ for the entire follow-up period, clopidogrel $75 \mathrm{mg}$ for 6 weeks and standard medication for the modifiable cardiovascular risks including diabetes mellitus, hypertension and hyperlipidemia.

\section{Learning curve analysis}

The learning curve effect was analyzed using a data splitting method. ${ }^{11}$ The outcome data of all 95 patients were split into quarters according to chronological sequence. Variables including patient age, degree of stenosis, location of stenosis, event-to-stenting interval, occurrence of technical problems during the procedure, technical failure and guidewire/ angioplasty-related hemorrhagic complications within 30 days were included for analysis. Differences between the groups of quarters were studied using the Mann-Whitney test for continuous variables and the $\chi^{2}$ test for categorical variables for trend changes across the groups.

\section{RESULTS}

\section{Patient demographics and lesion characteristics}

There were 68 men and 27 women (mean age $64.7 \pm 10.6$ years, median 65 , range $34-84)$ who presented with stroke $(n=41)$ or TIA $(\mathrm{n}=54) ; 41$ had hypertension, 46 had hypercholesterolemia, 29 had diabetes and 23 were smokers. The median NIHSS score was 2 and the median mRS score was 2 . The mean degree of stenosis was $75.5 \pm 10.3 \%$ (median $74 \%$, range 50 $99 \%)$. The lesion was located in the ICA in 26 cases $(27.6 \%)$, the ICA and MCA in 11 cases (11.5\%), M1 of the MCA in 37 cases $(38.9 \%), \mathrm{M} 2$ of the MCA in 3 cases (3.1\%), the basilar artery in 10 cases $(10.5 \%)$ and the vertebral artery in $8(8.4 \%)$. The event-to-stenting interval was $<30$ days in 58 patients $(61.1 \%)$ and $>30$ days in 37 (38.9\%).

\section{Study endpoints}

Periprocedural major stroke or death within 30 days occurred in four of the 95 patients (4.2\%), including three major ipsilateral guidewire- or angioplasty-related hemorrhage and one major ipsilateral ischemic stroke (seventh patient), all of which resulted in death. The etiology and mechanism of bleeding in each of 
these three hemorrhagic complications differed; the same mistake was not made twice. The first major hemorrhage (eighth patient) was a subarachnoid hemorrhage from the mid basilar artery which occurred after a second angioplasty for a $87 \%$ stenosis. A $3 \mathrm{~mm}$ balloon was used for the basilar artery of $3.2-3.4 \mathrm{~mm}$ diameter after an initial failure of angioplasty using a $2.75 \mathrm{~mm}$ balloon. The second case of major hemorrhage (48th patient) was due to dissection of a M1 segment with the micro guidewire during an attempt to recannulate a $90 \%$ stenosis at M1 for stent placement. Angioplasty had been performed at the M1 stenosis and the track was subsequently lost. The third case of major hemorrhage (66th patient) was due to perforation of a perforator at M2 with the micro guidewire during angioplasty. There were five cases of periprocedural minor stroke $(5.3 \%)$, which included two cases of minor contralateral ischemic stroke with CT evidence of a small new infarct (mRS 1 and 3, respectively), two cases of minor ipsilateral ischemic stroke with CT and MRI evidence of a small new infarct (mRS 1 and 3, respectively) and one case of minor ipsilateral hemorrhage due to hyperperfusion (mRS 3 ) with CT evidence of significant improvement in cerebral perfusion and a small amount of intraventricular bleeding. These five cases of periprocedural minor stroke all resulted in good clinical recovery. In total, periprocedural stroke occurred in nine patients $(9.5 \%)$, periprocedural death occurred in four patients $(4.2 \%)$ and periprocedural stroke or death occurred in nine patients $(9.5 \%)$.

In the five patients with periprocedural major or minor ischemic stroke, the event-to-stenting interval was $<30$ days in three patients $(60 \%)$ and $>30$ days in two $(40 \%)$. There was no difference in the risk of periprocedural ischemic stroke between an event-to-stenting interval of $<30$ days and $>30$ days $(5.2 \%$ vs $5.4 \%$; two-tailed $\mathrm{p}=1.00$, Fisher exact test).

Technical problems were encountered sporadically during the procedure in 11 patients $(11.6 \%)$, essentially in patients with tortuous vascular morphology along the vascular access path leading to the stenosis which caused difficulty in advancement of instruments and subsequent malfunction of instruments or symptoms of patients (table 1). With the use of intracranial guiding catheters to overcome unfavorable vascular morphology in the last 35 patients of the series, technical problems were no longer encountered.

The procedure was completed in 89 of the 95 patients (technical success rate 93.7\%). Technical failure of the procedure occurred in six patients due to problems encountered during the procedure in four patients $(66.7 \%)$, including TIA and failure to manipulate the balloon catheter across the stenosis, and to procedure-related hemorrhagic complication in two patients $(33.3 \%)$ (table 1$)$. The symptoms of TIA were detected during the procedure when they occurred because the patients were not sedated. The procedures were terminated when a TIA occurred and the patients recovered from the symptoms afterwards. There was no evidence of cerebral infarction on follow-up imaging.

At the time of analysis in February 2012, these 89 patients had been followed for a mean of $38.9 \pm 22.7$ months (median 40.8, range $0.2-72,3463$ patient-months) after stenting. Six patients died of unrelated causes from the first to the fifth year. Events of stroke or death are presented in table 2. During the first year of follow-up three patients had a minor contralateral ischemic stroke (mRS 2), during the fourth year one patient had a minor ipsilateral ischemic stroke (mRS 3 ) and during the fifth year one patient had a minor ipsilateral ischemic stroke (mRS 3). The probability of recurrent ipsilateral ischemic stroke following angioplasty and stenting was $3.1 \%(3 / 95)$ within 30 days and 0 from 30 days to 1 year. The cumulative probability of all stroke at 1 year (including periprocedural stroke within 30 days) was $9.5 \%$ (9/95). Throughout the follow-up period of 3463 patient-months the risk of recurrent ipsilateral ischemic stroke following treatment with stenting was $0.7 \%$ per patient per year (2/ 3463 patient-months).

\section{Outcome of medical control group}

In 45 patients with stenosis $\geq 70 \%$ who were treated with medical therapy, four (8.9\%) developed ipsilateral ischemic stroke within 30 days and eight (17.8\%) developed ipsilateral ischemic stroke within the first year. The cumulative probability

Table 1 Technical problems encountered during procedure and causes of procedure failure

\begin{tabular}{|c|c|c|c|c|}
\hline $\begin{array}{l}\text { Patient } \\
\text { sequence }\end{array}$ & $\begin{array}{l}\text { Stenosis } \\
\text { location }\end{array}$ & $\begin{array}{l}\text { Stenosis } \\
\text { degree }\end{array}$ & Technical problem encountered during the procedure & Cause of procedure failure \\
\hline 4 & ICA and MCA & $50 \%$ & $\begin{array}{l}\text { Difficult stent tracking and delivery, fracture core of stent delivery } \\
\text { system }\end{array}$ & \\
\hline 5 & ICA & $60 \%$ & $\begin{array}{l}\text { Nose cone bending caused stent sheath kinking and stretching } \\
\text { during stent deployment }\end{array}$ & \\
\hline 7 & ICA & $60 \%$ & Stretching of stent sheath during stent deployment & \\
\hline 8 & $\mathrm{BA}$ & $75 \%$ & & Arterial rupture after angioplasty \\
\hline 15 & ICA and MCA & $50 \%$ & TIA during manipulation of balloon catheter across stenosis & TIA \\
\hline 27 & ICA & $90 \%$ & $\begin{array}{l}\text { Nose cone trapped between guidewire and stent tip after stent } \\
\text { deployment }\end{array}$ & \\
\hline 42 & ICA & $75 \%$ & $\begin{array}{l}\text { Difficult stent tracking and delivery, fracture core of stent delivery } \\
\text { system, TIA }\end{array}$ & TIA \\
\hline 44 & MCA & $83 \%$ & TIA & \\
\hline 47 & ICA and MCA & $96 \%$ & Failure passage of balloon across stenosis & Failure passage of balloon \\
\hline 48 & MCA & $90 \%$ & Kinking of balloon catheter after guidewire removal & \\
\hline 56 & MCA & $70 \%$ & $\begin{array}{l}\text { Transient blindness and severe headache during stent system } \\
\text { advancement }\end{array}$ & \\
\hline 59 & MCA & $87 \%$ & Transient blindness during stent system advancement & TIA \\
\hline 66 & ICA & $75 \%$ & & $\begin{array}{l}\text { Perforation of M2 perforators by guidewire } \\
\text { during angioplasty }\end{array}$ \\
\hline
\end{tabular}

BA, basilar artery; ICA, internal carotid artery; MCA, middle cerebral artery; TIA, transient ischemic attack. 
Table 2 Stroke or death after 30 days in patients with Wingspan successfully placed

\begin{tabular}{|c|c|c|c|c|c|}
\hline \multirow[b]{2}{*}{ Event } & \multicolumn{5}{|c|}{ Incidence $(\%)$ of events occurring during the period of assessment } \\
\hline & 30 days to 1 year & 2nd year & 3rd year & 4th year & 5 th year \\
\hline No of patients evaluated & 75 & 63 & 49 & 37 & 17 \\
\hline $\begin{array}{l}\text { Major hemorrhagic stroke in } \\
\text { related territory }(\mathrm{mRS}>3)\end{array}$ & 0 & 0 & 0 & 0 & 0 \\
\hline $\begin{array}{l}\text { Major ischemic stroke in } \\
\text { related territory }(\mathrm{mRS}>3)\end{array}$ & 0 & 0 & 0 & 0 & 0 \\
\hline $\begin{array}{l}\text { Minor hemorrhagic stroke in } \\
\text { related territory }(\mathrm{mRS} \leq 3)\end{array}$ & 0 & 0 & 0 & 0 & 0 \\
\hline $\begin{array}{l}\text { Minor ischemic stroke in } \\
\text { related territory }(\mathrm{mRS} \leq 3)\end{array}$ & 0 & 0 & 0 & 1 & 1 \\
\hline $\begin{array}{l}\text { Minor ischemic stroke in } \\
\text { unrelated territory }(\mathrm{mRS} \leq 3)\end{array}$ & 3 & 0 & 0 & 0 & 0 \\
\hline Stroke-related death & 0 & 0 & 0 & 0 & 0 \\
\hline Unrelated death & $\begin{array}{l}1 \\
\text { Ruptured intracranial } \\
\text { aneurysm in non-target } \\
\text { territory }\end{array}$ & $\begin{array}{l}1 \\
\text { Carcinoma of stomach } \\
\text { and aspiration pneumonia }\end{array}$ & $\begin{array}{l}2 \\
\text { Bronchogenic } \\
\text { carcinoma, heart failure }\end{array}$ & $\begin{array}{l}1 \\
\text { Carcinoma of } \\
\text { pancreas }\end{array}$ & $\begin{array}{l}1 \\
\text { Acute gastrointestinal bleeding } \\
\text { while on aspirin alone }\end{array}$ \\
\hline
\end{tabular}

of recurrent ipsilateral stroke at 1 year was $17.8 \%$. After a mean follow-up of 42.2 months or 1881 patient-months, the risk of recurrent ipsilateral ischemic stroke following medical therapy was $5.1 \%$ per patient per year (6/1881 patient-months).

\section{Learning curve analysis}

The chronological sequence of occurrence of periprocedural complications, technical failures of the procedure and technical problems during the procedure are shown in figure 1. The results of data splitting analysis are shown in table 3 . Variables including patient age, degree of stenosis, location of stenosis and event-to-stenting interval were not significantly different across the four quarters except for those highlighted. The rates of procedural problems, technical failures and guidewire- or angioplasty-related hemorrhage were not significantly different in the first three quarters but fell to zero in the fourth quarter, indicating a trend change towards technical maturation and the absence of guidewire- or angioplasty-related mistakes in the fourth quarter. Although the trend change in the technical failure rate and guidewire/angioplasty-related hemorrhagic complication rate in the fourth quarter was not statistically significant, this could be because the rates were too low to show a difference.

\section{DISCUSSION}

The clinical value of angioplasty and stenting in the prevention of recurrent stroke in patients with intracranial atherosclerotic stenosis has been called into question since the publication of the results of the SAMMPRIS trial. The safety of stenting, as revealed by the high periprocedural rates of stroke and death in the SAMMPRIS trial, has been a key concern. Because further evidence from another large-scale study is unlikely to be available in the near future, scepticism about the safety of stenting with the Wingspan device is likely to last for a while. Given such a background, it is important to examine the evidence obtained so far before we abandon stenting for safety reasons.

For a procedure involving multiple passages of guidewires and instruments through a highly stenotic atherosclerotic lesion in an environment of tortuous vascular course and friable perforators, the requirement of a learning curve to achieve technical maturity

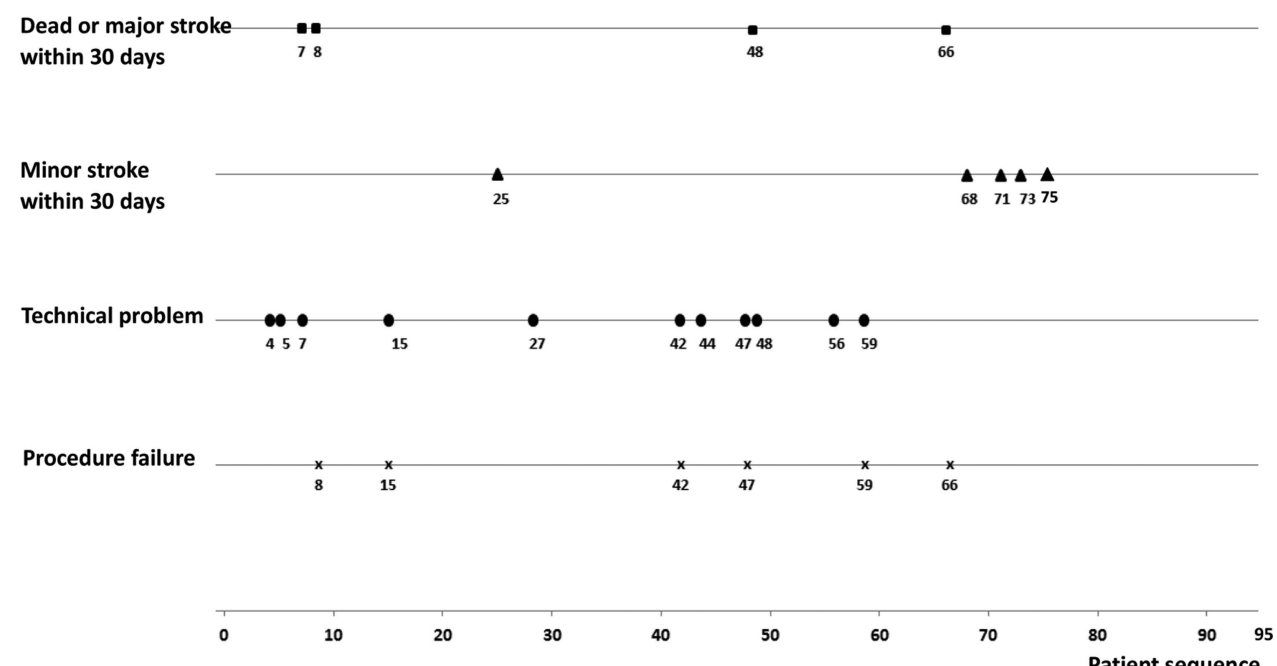

Figure 1 Occurrence of study endpoints in chronological sequence. 
Table 3 Leaning curve analysis using data splitting method

\begin{tabular}{|c|c|c|c|c|c|}
\hline Variables & 1st quarter & 2nd quarter & 3rd quarter & 4th quarter & Trend difference across quarters \\
\hline Patient sequence (patient no) & $1-24(24)$ & $25-48(24)$ & $49-72(24)$ & $73-95(23)$ & \\
\hline Age $($ mean $\pm S D)$ & $67.46 \pm 10.484$ & $62.75 \pm 11.433$ & $62.13 \pm 10.999$ & $66.57 \pm 9.336$ & No difference across quartersp $>0.085$ \\
\hline $95 \% \mathrm{Cl}$ & 63.03 to 71.89 & 57.92 to 67.58 & 57.48 to 66.77 & 62.53 to 70.6 & \\
\hline Degree of stenosis (mean \pm SD) & $69.96 \pm 12.539$ & $77.82 \pm 8.368$ & $76.39 \pm 9.942$ & $77.91 \pm 8.286$ & Difference between 1st and 2nd quarter, $\mathrm{p}=0.033$. \\
\hline $95 \% \mathrm{Cl}$ & 64.53 to 75.38 & 74.29 to 81.35 & 72.19 to 80.59 & 74.24 to 81.58 & No difference across other quarters \\
\hline \multicolumn{6}{|l|}{ Location } \\
\hline MCA & 10 & 16 & 15 & 10 & \multirow{3}{*}{$\begin{array}{l}\text { Difference between } 1 s t \text { and } 2 \text { nd quarter in } \\
\text { frequency of location at VBA, } p=0.023 \text {. No } \\
\text { difference across other quarters }\end{array}$} \\
\hline ICA & 6 & 7 & 5 & 8 & \\
\hline VBA & 8 & 1 & 4 & 5 & \\
\hline Event to stenting $<30$ days (rate) & $10(41.7 \%)$ & $15(62.5 \%)$ & $14(58.3 \%)$ & $18(78.3 \%)$ & $\begin{array}{l}\text { Difference between 1st and 4th quarter, } p=0.011 \text {. } \\
\text { Difference between } 4 \text { th quarter and the rest, } \\
p=0.05\end{array}$ \\
\hline Procedural problem (rate) & $4(16.7 \%)$ & $5(20.8 \%)$ & $2(8.3 \%)$ & 0 & $\begin{array}{l}\text { Difference between } 4 \text { th quarter and the rest, } \\
p=0.046\end{array}$ \\
\hline Technical failure (rate) & $2(8.3 \%)$ & $2(8.3 \%)$ & $2(8.3 \%)$ & 0 & No difference across quarters, $p>0.33$ \\
\hline $\begin{array}{l}\text { Guidewire- or angioplasty-related } \\
\text { hemorrhagic complication <30 days } \\
\text { (rate) }\end{array}$ & $1(4.2 \%)$ & $1(4.2 \%)$ & $1(4.2 \%)$ & 0 & No difference across quarters, $p=1$ \\
\hline
\end{tabular}

ICA, internal carotid artery; MCA, middle cerebral artery; VBA, vertebrobasilar artery.

and avoid guidewire/angioplasty-related complications is not an unreasonable speculation. The importance of a learning curve factor in intracranial stenting has been highlighted in a study which showed that stenting performed at low enrollment sites ( $<10$ patients) was associated with a higher risk of stroke or death within 30 days than those at a high enrollment site. ${ }^{12}$ In a study to investigate the relationship between physician and site experience and the risk of 30-day hemorrhagic strokes in the SAMMPRIS trial, it was found that high enrolling sites ( $\geq 12$ patients) tended to have lower rates of hemorrhagic stroke than low enrolling sites ( $<12$ patients) $(2.7 \%$ vs $9.8 \%, \mathrm{p}=0.043) .{ }^{13}$ However, the authors of the study also pointed out that interventionists with higher numbers $(>10)$ of Wingspan cases submitted for credentialing tended to have higher rates of periprocedural hemorrhagic or ischemic complications than those with $<10$ cases $(19.0 \%$ vs $9.9 \%, \mathrm{p}=0.11$ ), although the difference was not statistically significant. Based on this finding, they concluded that interventionists credentialed with less Wingspan experience were not responsible for the high rate of periprocedural stroke in the SAMMPRIS trial. The statement that interventionists with higher numbers of Wingspan cases submitted for credentialing tended to have higher rates of periprocedural complications than those with lower number of cases' actually implied that more experienced interventionists tended to have more periprocedural complications. While such an implication could be misleading, it contradicted the earlier finding that high enrolling sites tended to have lower rates of hemorrhagic stroke. Such controversy indicates that the reliability of the use of the credentialing criteria of 10 cases of Wingspan use in assessing the experience of the interventionists is questionable. In fact, the credentialing criteria are themselves arbitrary and have not been validated. The use of 10 cases as the criterion for assessing the adequacy of experience with the Wingspan procedure could have been a gross underestimation. A low periprocedural complication rate of $5 \%$ had been achieved in a prospective study of 100 consecutive cases. ${ }^{14}$ This low complication rate was based on the experience of two experienced operators in a high enrollment center who had previous experience of at least 181 procedures of intracranial stenting. ${ }^{15}$ Despite such a high level of previous experience, guidewire- or angioplasty-related complications still occurred in two out of five cases of periprocedural complications in their Wingspan study, indicating that the Wingspan procedure is a technically risky procedure and demands a learning process.

The periprocedural complications in the SAMMPRIS trial were mainly due to ischemic stroke $(63.3 \%, 19 / 30)$, which was largely due to perforator stroke $(63.1 \%, 12 / 19)$ and others such as embolic, mixed perforator/embolic and stent occlusion. The other periprocedural complications were due to hemorrhagic stroke, which was either subarachnoid $(45.5 \%, 5 / 11)$ or intracerebral $(54.5 \%, 6 / 11)$. Five of the six cases of intracerebral hemorrhage $(83.3 \%)$ presented $\geq 4 \mathrm{~h}$ after stenting. All cases of fatal hemorrhage were due to intracerebral hemorrhage. The incidence of guidewire- or angioplasty-related hemorrhage was not specified. ${ }^{16}$ The pattern of etiology of periprocedural complications in our study was different from that seen in the SAMMPRIS trial. Periprocedural hemorrhagic complications in our study were largely due to guidewire- or angioplasty-induced hemorrhagic complications $(75 \%, 3 / 4)$; delayed intracerebral hemorrhage presenting $\geq 4 \mathrm{~h}$ after the procedure did not occur. Perforator stroke did not occur in any of our 51 cases of stenosis at the MCA and the 10 cases at the basilar artery. It was found in our previous study that stenting with the Wingspan device in the MCA did not pose an increased risk of new perforator infarcts on MRI. ${ }^{17}$

A comparison of the periprocedural complications in the current study and those in the SAMMPRIS trial shows a difference in the nature of at least some of the periprocedural complications between the two studies which could possibly be due to differences in the treatment protocol. Understanding the cause of the specific complications may help to identify solutions to prevent them from occurring. Guidewire- or angioplasty-related hemorrhage due to technical mistakes was the single most important cause of periprocedural major stroke or death $(75 \%$, $3 / 4$ ) in our study; the incidence of this complication could be reduced by not repeating the same mistakes through learning. The results of learning curve analysis showed a trend change towards no cases of angioplasty-related hemorrhage in the fourth quarter, indicating a favorable outcome of the learning 
process. Although it is possible that an angioplasty-related hemorrhage may occur later than the fourth quarter, there was still a trend change towards a lower incidence of this complication. Periprocedural minor stroke essentially consists of ischemic stroke $(4 / 5,80 \%)$ or minor ipsilateral hemorrhage $(1 / 5,20 \%)$; these events are probably intrinsic to the procedure itself due to microembolism or hyperperfusion, respectively, and are unrelated to technical maturity so probably could not be avoided. It was therefore not surprising to note that periprocedural minor strokes occurred in the later part of the series (68th to 75th patients). Our practice of using a moderate intraprocedural dose of intravenous heparin (2500 IU) to maintain an activated clotting time of $180-250 \mathrm{~s}$, avoiding the use of a multiple loading dose of preprocedural clopidogrel and use of a low dose of aspirin might possibly help to reduce the risk of periprocedural intracerebral hemorrhage. Such a medication regimen did not result in a higher risk of periprocedural ischemic stroke in our study. However, whether limiting the dose of antiplatelet medication is related to a reduced risk of periprocedural intracerebral hemorrhage or an increased risk of ischemic stroke would require further study, perhaps involving the use of point-of-care assessment of platelet function inhibition. ${ }^{18}$ Ipsilateral ischemic stroke occurred in three of the nine cases of periprocedural stroke (33.3\%), a rate substantially lower than that in the SAMMPRIS study $(69.7 \%, 23 / 33)$. Our practice of performing the procedure without general anesthesia or sedation allowed patients to remain fully conscious and enabled us to stop the procedure early on detection of ischemic symptoms during the procedure. Although such practice led to technical failure of the procedure in four patients in our study, it might help to prevent the development of ischemic infarction and reduce the incidence of ipsilateral ischemic stroke. On the other hand, the advantage of general anesthesia in terms of patient immobility is obvious. Although patient motion was not a concern in our study, it can lead to increased complexity of the case and therefore potentially more complications such as perforation and dissection. The reason for the absence of periprocedural perforator stroke in our study is not known, but it is not unreasonable to speculate that a short inflation time during angioplasty could be a contributory factor, although further studies are required to confirm this.

To evaluate the degree of protection offered by stenting in preventing the occurrence of ipsilateral ischemic stroke, we compared the outcome of our patients with those treated with medical therapy in the same period as a control. In our control group the risk of ipsilateral ischemic stroke was $8.9 \%$ within 30 days and $17.8 \%$ within 1 year, which was comparable to the historical control subgroup of 206 patients in the WarfarinAspirin Symptomatic Intracranial Disease (WASID) trial with $\geq 70 \%$ intracranial stenosis treated with warfarin or aspirin in which the cumulative probability of ipsilateral ischemic stroke was $18 \%(95 \%$ CI $13 \%$ to $24 \%)$ at 1 year. ${ }^{19}$ In the medically treated patients in the SAMMPRIS trial who received continuous daily aspirin in a dose of $325 \mathrm{mg}$, daily clopidogrel in a dose of $75 \mathrm{mg}$ for 90 days and medication for risk factors, the risk of ipsilateral ischemic stroke was $4.4 \%$ within 30 days and $10.1 \%$ within 1 year, lower than those in our control group and that in the WASID subgroup. The risk of recurrent ipsilateral ischemic stroke after stenting in our study was 3.1\% within 30 days and 3.1\% within 1 year, and tended to be lower than that in our control group and in the medically treated groups in the other two studies. After 1 year the risk of recurrent ipsilateral ischemic stroke following stenting also tended to be lower than following medical therapy in our study $(0.7 \%$ vs $5.1 \%$ per patient per year). These results indicate that stenting might be valuable in preventing the occurrence of recurrent ipsilateral ischemic stroke. However, a randomized controlled trial, preferably with modified treatment protocols catering for a reduction in periprocedural complications and involvement of an experienced interventionist, is needed to confirm this.

We enrolled patients with an event-to-stenting time of $>30$ days in 37 patients (38.9\%), which was different from the enrollment policy of the SAMMPRIS trial. Enrollment of this group might decrease the risk of periprocedural intracerebral hemorrhage due to post-stenting reperfusion of recently infarcted brain. The fact that this was a single-center study also limited its generalizability since a single center could have a learning curve that is better or worse than another.

In conclusion, there may be a learning curve for mastering Wingspan stenting for intracranial atherosclerosis. Understanding the cause of periprocedural complications may help to identify solutions to prevent them from occurring, and limiting the provision of this treatment to those centers with a high case load may be a reasonable consideration for periprocedural safety.

Acknowledgements The authors thank Mr Clinton Wong for his technical support in the treatment procedures and Miss Tiffany Lau for data management and analysis.

Contributors All authors made substantial contributions to the conception and design of the study, acquisition of data or analysis and interpretation of data; drafting the article or revising it critically for important intellectual content; and final approval of the manuscript.

Funding This study was partly supported by the Vascular and Interventional Radiology Foundation, which is a charitable organization. It was not sponsored by any other grant or funding from any commercial company.

\section{Competing interests None.}

Ethics approval Ethics approval was obtained from the Clinical Research Ethics Committee of The Chinese University of Hong Kong.

Provenance and peer review Not commissioned; externally peer reviewed.

Open Access This is an Open Access article distributed in accordance with the Creative Commons Attribution Non Commercial (CC BY-NC 3.0) license, which permits others to distribute, remix, adapt, build upon this work non-commercially, and license their derivative works on different terms, provided the original work is properly cited and the use is non-commercial. See: http://creativecommons.org/ licenses/by-nc/3.0/

\section{REFERENCES}

1 Sacco RL, Kargman DE, Gu Q, et al. Race-ethnicity and determinants of intracranial atherosclerotic cerebral infarction. The Northern Manhattan Stroke Study. Stroke 1995;26:14-20

2 Broderick J, Brott T, Kothari R, et al. The Greater Cincinnati/Northern Kentucky Stroke Study: preliminary first-ever and total incidence rates of stroke among blacks. Stroke 1998;29:415-21.

3 Wong KS, Huang YN, Gao S, et al. Intracranial stenosis in Chinese patients with acute stroke. Neurology 1998;50:812-13.

4 Qureshi Al, Feldmann E, Gomez CR, et al. Consensus conference on intracranial atherosclerotic disease: rationale, methodology, and results. J Neuroimaging 2009;19:1S-10S.

5 Chimowitz MI, Lynn MJ, Derdeyn CP, et al. Stenting versus aggressive medical therapy for intracranial arterial stenosis. N Engl J Med 2011;365:993-1003.

6 Bose A, Hartmann M, Henkes $\mathrm{H}$, et al. A novel, self-expanding, nitinol stent in medically refractory intracranial atherosclerotic stenoses: the Wingspan study. Stroke 2007:38:1531-7.

7 Fiorella D, Levy El, Turk AS, et al. US multicenter experience with the wingspan stent system for the treatment of intracranial atheromatous disease: periprocedural results. Stroke 2007;38:881-7.

8 Zaidat 00, Klucznik R, Alexander MJ, et al. NIH Multi-center Wingspan Intracranial Stent Registry Study Group. The NIH registry on use of the Wingspan stent for symptomatic 70-99\% intracranial arterial stenosis. Neurology 2008; 70:1518-24.

9 Gray WA, Yadav JS, Verta P, et al. The CAPTURE registry: predictors of outcomes in carotid artery stenting with embolic protection for high surgical risk patients in the early post-approval setting. Catheter Cardiovasc Interv 2007; 70:1025-33. 


\section{Ischemic stroke}

10 Topakian R, Strasak AM, Sonnberger M, et al. Timing of stenting of symptomatic carotid stenosis is predictive of 30-day outcome. Eur J Neurol 2007;14:672-8.

11 Ramsay CR, Grant AM, Wallace SA, et al. Assessment of the learning curves in health technologies: a systematic review. Int I Technol Assess Healthcare 2000;16:1095-108.

12 Nahab F, Lynn MJ, Kasner SE, et al. Risk factors associated with major cerebrovascular complications after intracranial stenting. Neurology 2009;72:2014-19.

13 Derdeyn CP, Fiorella D, Lynn MJ, et al. Impact of operator and site experience on outcomes after angioplasty and stenting in the SAMMPRIS trial. J Neurolntervent Surg. 2013;5:528-33.

14 Jiang WJ, Yu W, Du B, et al. Outcome of patients with $\geq 70 \%$ symptomatic intracranial stenosis after Wingspan stenting. Stroke 2011;42:1971-5.
15 Jiang WJ, Du B, Leung TW, et al. Symptomatic intracranial stenosis: cerebrovascular complications from elective stent placement. Radiology 2007;243:188-97.

16 Fiorella D, Derdeyn CP, Lynn MJ, et al. Detailed analysis of periprocedural strokes in patients undergoing intracranial stenting in Stenting and Aggressive Medical Management for Preventing Recurrent Stroke in Intracranial Stenosis (SAMMPRIS). Stroke 2012;43:2682-8.

17 Leung TW, Yu SCH, Lam WWM, et al. Would self-expanding stent occlude middle cerebral artery perforators? Stroke 2009;40:1910-12.

18 Gibbs NM. Point-of-care assessment of antiplatelet agents in the perioperative period: a review. Anaesth Intensive Care 2009;37:354-69.

19 Kasner SE, Chimowitz MI, Lynn MJ, et al. Predictors of ischemic stroke in the territory of a symptomatic intracranial arterial stenosis. Circulation 2006;113:555-63. 